\title{
IGREJAS E MOVIMENTOS INCLUSIVOS
}

\author{
Churches and inclusive movements
}

\author{
JUNQUEIRA, Sérgio Rogério Azevedo ${ }^{1}$ \\ IPFER - Paraná / Brasil \\ BRITO FILHO, Acir ${ }^{2}$ \\ FURB - Santa Catarina / Brasil
}

\begin{abstract}
RESUMO: Este artigo é o resultado da pesquisa do Programa Formação Inicial e Continuidade para a diversidade no projeto Diversidade no Espaço Escolar. este estudo é consequência do projeto Gênero e Orientação Sexual no Ensino Religioso que ocorreu no período de 2007 a 2016. O atual projeto tem por objetivo identificar e analisar, nas comunidades cristãs, a presença da comunidade LGBTI (Lésbicas, Gays, Bissexuais, Transexuais, Travestis e Intersexuais) e sua relação com igrejas e movimentos que são formados e ou a acolhem. Com a intenção de apoiar o trabalho de profissionais da educação que atuam junto a adolescentes e jovens, que estão dialogando sobre sua identidade sexual e seu pertencimento religioso. Esta é uma pesquisa qualitativa, descritiva e documental, compreendendo que documento é "qualquer suporte que contenha informação registrada, formando uma unidade, que possa servir para consulta, estudo ou prova”. Incluem-se nesse universo os documentos impressos, os manuscritos, os registros audiovisuais e sonoros, as imagens, entre outros.
\end{abstract}

Palavras-chave: Diversidade; Diversidade Sexual, LGBT.

ABSTRACT: This article is the result of the research of the Initial Formation and Continuity Program for Diversity in the Diversity in School Space project. this study is a consequence of the project Gender and Sexual Orientation in Religious Education that occurred between 2007 and 2016. The current project aims to identify and analyze in the Christian communities the presence of the LGBTI community (Lesbians, Gays, Bisexuals, Transsexuals, Travestis and Intersexuals) and their relationship with churches and movements that are formed and / or welcomed. With the intention of supporting the work of educational professionals who work with adolescents and young people, who are discussing their sexual identity and their religious belonging. This is a qualitative, descriptive and documentary research, understanding that document is "any medium that contains registered information, forming a unit, that can serve for consultation, study or proof." Included in this universe are printed documents, manuscripts, audiovisual and sound records, images, among others.

Keywords: Diversity; Sexual Diversity, LGBT.

\footnotetext{
1 Livre Docente em Ciência da Religião; Doutor em Educação. Licenciado em Pedagogia. Diretor do IPFER. E-mail: srjung@gmail.com

2 Engenheiro Civil, Mestre em Engenharia Civil; Bacharelando de Teologia, Pesquisador do IPER. Professor da Universidade Regional de Blumenau. E-mail: acirfilho@gmail.com
}

REVISTA RELEGENS THRÉSKEIA - 2018 - UFPR - UEPA 


\section{Introdução}

Este artigo é o resultado da pesquisa do Programa Formação Inicial e Continuidade para a diversidade no projeto Diversidade no Espaço Escolar. Este estudo é consequência do projeto Gênero e Orientação Sexual no Ensino Religioso que ocorreu no período de 2007 a 2016. O atual projeto tem por objetivo identificar e analisar, nas comunidades cristãs, a presença da comunidade LGBTI (Lésbicas, Gays, Bissexuais, Transexuais, Travestis e Intersexuais) e sua relação com igrejas e movimentos que são formados e ou a acolhem. Com a intenção de apoiar o trabalho de profissionais da educação que atuam junto a adolescentes e jovens, que estão dialogando sobre sua identidade sexual e seu pertencimento religioso. Esta é uma pesquisa qualitativa, descritiva e documental (GIL, 2002), compreendendo que documento é "qualquer suporte que contenha informação registrada, formando uma unidade, que possa servir para consulta, estudo ou prova" (ABNT, 2002). Incluem-se nesse universo os documentos impressos, os manuscritos, os registros audiovisuais e sonoros, as imagens, entre outros (APPOLINÁRIO, 2009, 67).

Nesta etapa da pesquisa preocupa-se em compreender a existência humana, que desde as primeiras civilizações historicamente registradas até a atualidade, é marcada por desafios. Para a garantia da sua sobrevivência foi necessário investigar e dominar os efeitos da natureza, fazendo um incessante esforço para aprimorar as técnicas de avaliação dos fenômenos.

Não se pode negligenciar que a humanidade é fruto de uma evolução de caráter biológico, mais lenta, e também de caráter cultural, que envolve mudanças de hábito. Esta evolução - ou transformação - influi, direta ou indiretamente, no que a sociedade classifica como "necessário" e "fundamental", e é chamada de Evolucionismo Cultural (PEDROSA, 2008, 9). Ao organizar a vida diária, o ser humano cria hábitos (héxis), que geram atitudes, estabelecendo um sentido àquilo que faz e significado às coisas que o cercam. Tal especificidade e pessoalidade representam a própria maneira de ser e habitar o mundo. Entretanto, as mudanças culturais não estão necessariamente relacionadas, nas diversas partes do mundo e em sua gênese, já que os ambientes são distintos.

De todos os temas que sofreram imensas transformações culturais ao longo da 
história, a sexualidade - e todas as suas componentes - é com certeza um dos que mais intriga (MOSER, 2001, p. 21). É um assunto complexo e que, embora haja muitas pesquisas multidisciplinares e avançadas, em especial na psicanálise, há inegavelmente um tabu a este respeito, com destaque à orientação sexual e identidade de gênero, principalmente em sociedades cuja formação está baseada no patriarcalismo. Pode-se observar que, de algum modo, as principais religiões do mundo posicionam-se sobre a relação entre pessoas do mesmo sexo.

\section{Processo histórico}

Há uma corrente de pensamento psicanalítico que defende que heterossexualidade, homossexualidade ou bissexualidade não configuram escolha; a pessoa apenas vivencia ou nega seus sentimentos e atrações, já que “[...] a escolha do objeto sexual é profundamente enraizada no inconsciente e não depende de uma escolha consciente, nem de uma 'opção sexual' no sentido em que esta expressão é frequentemente utilizada" (QUINET \& JORGE, 2013, p. 11).

A orientação sexual se desenvolve por um complexo conjunto de fatores biopsíquicos que determinam o interesse sexual de um indivíduo. Sentimentos e sensações acontecem sem que se saiba explicá-los: uma pessoa heterossexual não escolhe sentir prazer em uma relação com o gênero oposto, assim como também não escolhe não desejar ter uma relação sexual com uma pessoa do mesmo gênero.

Então, a sexualidade pode ser definida também como um espaço de construção do sujeito/pessoa, de sua autonomia, império das decisões individuais íntimas que se estruturam em lógicas menos padronizadas e gerais, baseadas em trajetórias afetivas, não necessariamente conjugais. Não está limitada, portanto, à expressão meramente genital, que representa apenas um aspecto de nossa identidade como seres sexuais. Este fato fica mais claro quando se produz uma discussão da heterossexualidade e da homossexualidade sob a ótica das diferentes referências religiosas e da ética.

Apesar dos avanços científicos das ciências humanas, que promoveram uma mudança de perspectiva sobre o conceito de normalidade, que também há décadas suprimiu as relações erótico-afetivas homossexuais da caracterização de distúrbio psiquiátrico, a sociedade ainda mantem atitudes de desrespeito ao outro, o que é diferente, particularmente na forma de viver sua sexualidade.

Ainda está presente uma "heteronormatividade", que é considerar como 
"normal", "correto", somente as relações heterossexuais. Pessoas, fatos e situações que não se enquandram nesta "normalidade" são considerados “incorretos" e consequentemente ignorados, discriminados e ou excluídos.

Em algumas tradições, a expressão da sexualidade é regulada por um conjunto de dogmas e princípios morais, que muitas vezes são seguidos sem considerar a prática e a visão do mundo ocidental moderno. Então, a sexualidade implica em um sentimento, espontâneo e indesejado ao mesmo tempo, de contradição entre duas posições, uma antinomia, fazendo fluir uma peculiar sensação de desafio e simultaneamente de contradição.

Não há como determinar se as religiões assumiram consentimentos e proibições a comportamentos sexuais vigentes, para em seguida estabelecer novos rumos, ou se houve uma intervenão à prática sexual desde o princípio. Não se pode afirmar com clareza quando as regras sexuais surgiram (ENDSJO, 2014, p. 13).

\section{Leitura cristã}

Por ser controlada pelas instituições religiosas, através de princípios morais e dogmas, a sexualidade é assunto que tende a ser pouco debatido, por vezes evitado, causando certo temor por causa das implicações relativas ao prazer. As exepriências relativas à sexualidade e à religiosidade são domínios que fornecem, em diferentes momentos da vida, mapas culturais que orientam e modelam a subjetividade e a vida dos sujeitos. Conduzem a distintas formas de percepção e de vivência do mundo e das relações sociais, que são continuamente reelaboradas no fluxo da experiência social. Assim, nas interações e na inserção em determinados contextos, os sujeitos encontram campos de possibilidades para a construção de si.

A experiência religiosa representa parte de uma conexão com outros domínios da vida social, como o percurso sexual amoroso, a história familiar e a etapa da vida. A trajetória religiosa varia em momentos de maior ou menor aproximação da doutrina e de valores religiosos, dependendo do contexto no qual se dá. Na religião, a religação entre masculino e feminino certas vezes se apresenta como fundante da totalidade; noutras, como discurso de poder de uma instância - a masculina - sobre a outra - a feminina -, gerando movimentos de subordinação e autoritarismo. Parece prevalecer, à primeira vista, o contraste entre a representação erudita convencional "moderna" da religião como uma dimensão antiquada e pudica, se não abertamente repressiva, e a vida 
coletiva atualizada e expressiva, possível de autenticidade subjetiva, o que caracteriza, sem dúvida alguma, uma antítese.

Para as comunidades cristãs a Bíblia, o texto religioso, assume um papel fundamental para apoiar orientações às suas doutrinas, utilizando-se de suas citações para sustentar seus ensinamentos acerca da lei natural. De forma geral, os textos destas expressões religiosas afirmam que, desde o livro do Gênesis (Gn), do Primeiro (ou Antigo) Testamento, até o fim do Segundo (ou Novo) Testamento, há uma oposição constante aos atos homogenitais.

Encontram-se na Bíblia vários textos que repudiam a prostituição, heterossexual e homossexual, a exemplo do que se lê no Pentateuco - conjunto de livros do Primeiro Testamento -, em Lv 19, 29, que condena desonrar a filha prostituindo-a. Se houve o registro escrito desta proibição, certamente havia o costume (de prostituir a própria filha). A existência desta conduta (prostituir a própria filha!), está confirmada na passagem sobre a destruição de Sodoma, onde Ló, na tentativa de proteger seus hóspedes estrangeiros de uma multidão que desejava "cometer-lhes abusos", oferece as duas filhas virgens, para que os homens fizessem delas o que bem entendessem ( $\mathrm{Gn}$ 19, 1-8), mostrando o "[..] quão diferente a cultura de Lot era da nossa" (HELMINIAK, 1998, p. 41).

Na realidade, a expressão hebraica ונדעה (FRANCISCO, 2012, p. 55), presente na narrativa dos anjos que visitam Ló, está associada a "fazer-se saber" ou “conhecer", nem sempre com conotação sexual. Para Leers e Trasferetti:

\footnotetext{
Mesmo que o verbo usado "conhecer" significasse relações sexuais - o que tem de ser provado - seu sentido não poderia ser isolado do contexto claro de violência, humilhação, abuso de poder, rapto, estupro e lesão da sagrada lei da hospitalidade, que contrastava vivamente com o modo delicado e gentil de Abraão receber seus visitantes no capítulo anterior (LEERS E TRASFERETTI, 2002, p. 102).
}

Curiosamente, segundo outro relato bíblico, após jovem Davi vencer o filisteu (1 Sm 17, 48-51), Saul quer saber de quem ele é filho (1 Sm 17, 55-56). O próprio Saul o interpela, enquanto Davi ainda segurava a cabeça de seu oponente derrotado (1 Sm, 5758). Ao ver Davi, Jônatas "o amou como a si mesmo"; mais tarde, como Davi fez-se hóspede a convite de Saul, Jônatas fez um pacto com ele e despiu-se de seu manto, de sua roupa, de sua espada, de seu arco e de seu cinturão, entregando-os a Davi (1 Sm 18, 
1-4). Mais tarde, quando Saul, movido pela inveja, quis levar Davi à morte, Jonatas interveio, suplicou e conseguiu reverter as intenções do rei (1 Sm 19, 1-7). Que amor é este que faz o filho do rei despir-se de seus bens simbólicos mais importantes, que faz intervir pela vida do jovem?

No Segundo Testamento há várias controvérsias, a exemplo do que está

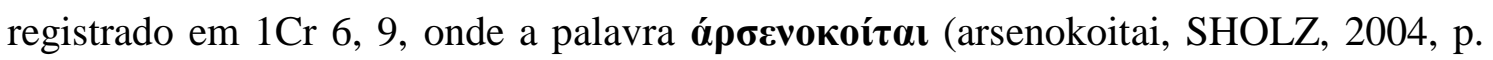
628) recebe vários significados. Na Edição Revista e Atualizada (RA) da Bíblia Sagrada, editada pela Sociedade Bíblica do Brasil (1993), é traduzida como "sodomitas" - aliás, “[...] uma escolha inadequada porque o termo não guarda relações diretas com o nome da cidade de Sodoma" (TORRES, 2012). Na Edição Catequética Popular, da Editora Ave Maria (Edição Claretiana, 2012), emprega-se o termo “devassos”. Na Tradução Ecumênica da Bíblia (TEB, 2015) e na versão da Editora Vozes (1982) encontra-se a expressão “pederastas”. Na Bíblia de Jerusalém (1998) pode ser lido “pessoas de costumes infames”. Na Bíblia do Peregrino (1997) a tradução emprega a palavra "homossexuais". É importante ressaltar que a expressão "homossexual" foi cunhada, em substituição a "pederasta", pelo jornalista, escritor e ativista dos direitos humanos, o austro-húngaro Karl-Maria Kertbeny, somente em 1869 (PAOLIELLO, in QUINET E JORGE, 2013, p. 33). Conclui-se que não há, portanto, convergência sobre o seu real significado.

Há indicações de que a expressão esteja relacionada a relações cultuais, já que:

As cidades de Corinto, destinatária da epístola de Paulo, e Éfeso, onde
Timóteo vivia, eram reconhecidos centros das religiões de fertilidade. Em
Corinto, adorava-se Afrodite (ou Vênus); em Éfeso, Artemisa (ou Diana).
Não se sabe ao certo, porém, se, na época de Paulo, esses cultos retinham,
nessas cidades, a força que haviam exibido em sua época de esplendor,
alguns séculos antes. É provável, contudo, que a obsessão sexual de outrora
ainda prevalecia nesses grandes centros urbanos, mesmo sem a íntima ligação
que essas cidades antes desfrutavam com as religiões de fertilidade
(TORRES, 2012)

Esta possibilidade inviabiliza qualquer referência às relações afetivas entre homossexuais da atualidade.

No Evangelho atribuído a Lucas (7, 1-10, com narrativa paralela em Mt 8, 510.13), quando Jesus entrou em Cafarnaum, aproximou-se dele um Centurião, que de tão simpático à nação israelita havia até construído uma sinagoga. Clamava por seu 


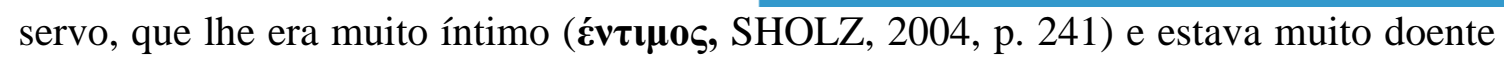

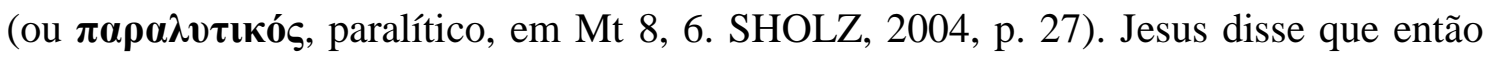
mostrasse o caminho de sua casa; o centurião, num gesto de pura humildade, disse-lhe que não era digno de que o Senhor (кv́pıє, SHOLZ, 2004, p. 27 e 242) entrasse em sua casa, bastaria que Ele dissesse uma palavra e seu servo estaria salvo. Admirado com tamanha fé, Jesus disse-lhe que seu servo estaria salvo assim que retornasse à sua casa.

Para a tradição cristã a procriação é um aspecto essencial da sexualidade humana; portanto, todos os atos sexuais devem possibilitar a concepção, em uma relação heterossexual, monogâmica e somente depois de instituída a formalidade da união, através do casamento. O esforço por fazer florescer uma descendência sólida é uma herança, também, do Exílio da Babilônia, período de deportação da classe dirigente, ocasionando à Judéia uma “[...] grave crise demográfica e cultural" (LIVERANI, 2008, p. 243-244).

Uma sociedade impactada pela invasão babilônica, em exílio, pode ter inspirado fortemente a escrita de primeira narrativa da criação, presente no Livro do Gênesis. Este entendimento da narrativa bíblica, presente nos ensinamentos religiosos, é empregado para condenar os atos denominados homogenitais, já que biologicamente não reproduzem a vida, assim como os métodos contraceptivos, a masturbação e as relações sexuais pré e extraconjugais.

De forma diversa, a cultura judaico-cristã perseguiu e condenou as práticas homoeróticas e todo tipo de conduta ou prática que não se aplicava a lógica do coito com finalidade reprodutiva, ou seja, a relação sexual exclusiva entre homem e mulher, tendo a reprodução como único fim legítimo (SOUZA, 2010, p. 14).

Com base nesta premissa é possível observar lideranças religiosas, frequentemente e fazendo uso da mídia, lançarem frases discriminatórias e preconceituosas contra pessoas homossexuais. Diante destas situações, a pessoa com orientação homossexual sofre da não aceitação de si, reprimindo sua sexualidade, buscando mascarar seus sentimentos, levando a um dramático isolamento sentimental (solitários em meio à multidão), provocando, em muitos caos, uma profunda neurose.

Pessoas com orientação homossexual são induzidas, por conta destas regulações religiosas e de preconceitos sociais - inegavelmente relacionados à religião -, a não se aceitaram, buscando mascarar seus sentimentos, distanciando-se de si mesmas 
(JUNQUEIRA et al., 2015, p. 20). Em decorrência, vislumbra-se uma "saída" no esforço de garantir uma imagem social aceitável, aproximando-se sexualmente de pessoas do gênero oposto (RAMIRES NETO, 2006, p. 120).

Este é, certamente, um caminho permeado pela incompletude, podendo gerar, em casos mais graves, um forte sentimento tirano de homofobia, em decorrência da negação que fazem de si, ao mesmo tempo em que assistem às inegáveis evidências de mudança nos costumes sociais. Explica-se: é crescente o número de pessoas, famosas ou não, que "saem do armário", ou seja, aceitam-se em sua plenitude, rejeitando o fato de terem que guardar um "grave segredo" (o termo é uma adaçtação da expressão coming out na língua inglesa). Passam então a manifestar em público sua autenticidade na maneira de ser, vestirem-se e de relacinarem-se erótico-afetivamente com outras pessoas. Diante do "amor não realizado" - por parte daquelas pessoas que negam sua essência -, há a formulação paranóica da reprovação condenatória, por pura projeção de ódio a um objeto negado, o amor homossexual (QUINET, in QUINET E JORGE, 2013, p. 96), como se fosse uma verdadeira praga a ser extinta.

Mais do que propor-se a ser o elo entre seres humanos e o invisível, a religião dita normas de comportamento e transmite visões de mundo que podem ser extremamente cruéis, contrariando seu princípio basilar de promoção da vida e da dignidade humana. A religiosidade estará incompleta se não compreender o indivíduo em seu direito de viver a sexualidade de modo a sentir-se íntegro, inteiro, de acordo com a sua disposição hétero ou homossexual, sem que tenha que passar pela angústia e pelo sofrimento de sentir preconceito de si mesmo.

Toda sociedade participa, passiva ou ativamente, de discussões sobre diversos assuntos, como economia, política, religião, conflitos internacionais e regionais, dentre outros temas. Estas discussões constituem uma ferramenta pedagógica nas escolas, contribuindo para a formação de um pensamento crítico nos sujeitos que estão em formação. Entretanto, a sexualidade continua sendo um tema silenciado nestes ambientes.

\section{Igrejas e Movimentos Inclusivos}

Os estudantes de ensino fundamental e médio são indivíduos em processo de descoberta da própria sexualidade, mas nem sempre a escola está disposta a refletir sobre este tema. Faz-se necessário refletir sobre a sexualidade, seus resultados políticos 
e religiosos, pois, como bem afirmou o filósofo alemão Nietzsche, "a sexualidade de uma pessoa se estende em grau e gênero até o ponto mais alto de seu espírito".

O espaço e o tempo educativos constituem um momento único, privilegiado e irrenunciável de debate, com vistas ao crescimento integral da pessoa, percebendo que as situações cotidianas e os indivíduos nelas inseridos são únicos, especiais. O ensino tem o potencial de desenvolver a capacidade de aprendizado, de respeito às diferenças, contribuindo para a compreensão e o enfrentamento dos constantes e complexos desafios históricos, frequentemente apresentados, tornando as e os estudantes capazes de promover transformações sociais, por meio da disponibilização dos conhecimentos adquiridos.

Tanto a preparação quanto a prática transformadora do éthos necessitam ser guiadas por uma intenção significadora, a ser apropriada pela atividade subjetiva do conhecimento, isto é, será necessário que cidadãs e cidadãos voltem a aproximar-se do senso de solidariedade e sejam educados para a responsabilidade. A palavra responsabilidade remete à capacidade de "dar respostas", o que significa posicionar-se sensivelmente perante os fatos da vida. Da mesma forma, o desenvolvimento de uma consciência ecológica e a redescoberta do transcendente/imanente, a construção de uma nova subjetividade com a revalorização da função materna, ou seja, a energia estruturadora que nos torna sensíveis a tudo o que está relacionado com a vida e a cooperação.

Assim, no modo sagrado das religiões a esperança é o desejo da vida para cada um de nós. Viver para cuidar, amar e proteger a todas as formas de vida. Isto significa a vida cuidando da vida e esta é a esperança! Do mesmo modo, mulheres, homens e crianças, árvores, rochas e rios são diferentes formas da manifestação de beleza do poema sagrado da criação; não há melhor nem pior, não há soberano nem serviçal. $\mathrm{O}$ que existe é um mundo partilhado, através de formas de vida cooperantes.

Então, é necessário desenvolver um olhar humanizante emergente nas grandes massas, característica dos ícones das principais religiões, refletido naqueles que se propõem a serem facilitadores de aprendizado e conhecimento. Espera-se, daqueles que fazem a escolha responsável pelo ensino, que se envolvam com uma profunda imersão na realidade das pessoas, criando condições para o respeito às distintas configurações humanas existentes. 
O posicionamento geral das igrejas cristãs a respeito das pessoas Lésbicas, Gays, Bissexuais, Transexuais e Travestis (LGBT), que as classificam como "pecadoras", tem contribuído para fomentar situações desastrosas de conflitos pessoais, além de contribuir fortemente para o preconceito. Entretanto, outro movimento construtivo tem surgido: a criação de movimentos inclusivos, principalmente nas igrejas históricas, assim como a formação de igrejas totalmente inclusivas.

O que diferencia uma igreja inclusiva das tradicionais são as pessoas que as frequentam, unidas por uma necessidade pulsante de acolhimento e respeito, onde podem partilhar momentos de estudos bíblicos e encontram forças para que elas possam enfrentar coletivamente o preconceito. A maior parte dos fiéis é formada por pessoas LGBT, que carregam consigo o histórico comum de discriminação, mas que não abrem mão de exercer a fé em suas crenças, presente em uma espiritualidade latente.

Exemplo de igreja cristã inclusiva, a Fraternidade Universal das Igrejas da Comunidade Metropolitana (FUICM) tem atuação mundial. Sediado na cidade norteamericana de Los Angeles, o Centro Mundial da FUICM é o elo de comunicação para todos os fiéis ao redor do planeta. Os escritórios centrais proporcionam diversos serviços, tais como administração financeira, planejamento de conferências, relações com os meios de comunicação, além de produção e distribuição de recursos de comunicação, que inclui a revista mensal "Mantendo-se em contato".

Com sua posição ecumênica, a FUICM tem um status de observadora oficial no Conselho Mundial de Igrejas (CMI); é membro do Conselho Latino-americano de Igrejas (CLAI), assim como do Conselho Norte-americano de Igrejas. Os estudantes da FUICM frequentam as principais faculdades de teologia, além dos cursos disponibilizados internamente por suas lideranças. A FUICM testemunha o Evangelho inclusivo de Jesus à comunidade LGBT em todo o mundo, sem fazer acepção de pessoas.

A Igreja da Comunidade Metropolitana no Brasil (ICM Brasil), membro da FUICM - do mesmo modo que demais Igrejas da Comunidade Metropolitana em todo o globo -, oferece uma oportunidade de reconciliação com Deus por meio do amor incondicional de Jesus, sem que a pessoa tenha que negar o dom divino da sua sexualidade. As teólogas e os teólogos da ICM proclamam que as Escrituras não condenam as relações amorosas e respeitosas entre homossexuais. 
Em todo o mundo, as ICM protestam contra políticas homofóbicas e leis discriminatórias na Europa, em toda a América, na Ásia e na África, testemunhando que "Deus não faz acepção de pessoas" (At 10, 34), que "Deus é amor: aquele que permanece no amor permanece em Deus e Deus permanece nele" (1Jo 4, 16) e que para um cristianismo autêntico, é indispensável a lei que diz "Amarás o teu próximo como a ti mesmo" (G1 5, 14 // Lv 19, 18).

Desde sua fundação, a ICM tem celebrado cerimônias de União Sagrada ou Bênção do Matrimônio a casais homossexuais, como meio de abençoar sua vida instituída em comunhão. Este posicionamento enérgico da ICM em prol dos direitos humanos fez com que sofresse ataques violentos por parte de seus opositores. Nos Estados Unidos, dezoito igrejas da ICM foram criminosamente incendiadas entre os anos de 1971 e 1985. Atualmente, muitas continuam sendo alvo de bombas e outras formas de ataques violentos.

A Igreja Acalanto, fundada em maio de 2002, é igualmente inclusiva, de denominação evangélica e liderada pelo pastor Victor Orellana, atualmente com 35 anos de idade. O principal objetivo da igreja é abrir as portas para pessoas LGBT que professam sua fé.

Para Orellana, as comunidades religiosas evangélicas tradicionais da década de 1990 apresentavam uma postura exageradamente agressiva em relação a pessoas LGBT. "Muitos [gays] sofriam dentro destas igrejas fundamentalistas", diz o pastor, que acredita que a Parada Gay (movimento de protesto e afirmação LGBT, que acontece anualmente nas principais cidades do Brasil e do mundo) ajudou no processo de visibilidade desta comunidade.

Orellana ainda defende que "Toda essa visibilidade [...] obrigou as comunidades evangélicas fundamentalistas brasileiras a terem uma postura mais suavizada em relação aos gays. Sei que hoje não existe tanta agressividade ao gay como no passado, por isso somos a favor que os gays saiam dos guetos e confinamentos e assumam seu papel na humanidade". Atualmente, a Acalanto tem um espaço para cultos na Zona Norte da cidade de São Paulo e outro em Brasília.

Durante a última edição da Parada da Diversidade LGBT de Curitiba, que ocorreu em novembro de 2016, além de toda a pluralidade de expressões e culturas, 
constatou-se a presença de um grupo pertencente à igreja inclusiva Comunhão Cristã Plena Graça.

Constata-se também a criação de movimentos inclusivos nas igrejas ditas históricas, como o grupo Diversidade Católica do Rio de Janeiro. Criado em 2008, tem por missão:

\footnotetext{
Promover e difundir a Boa Nova de Jesus Cristo, que é a participação no Reino de Deus, partilhando a experiência do amor de Deus junto a todos os fiéis que, em virtude de sua identidade e/ou orientação sexual, frequentemente são excluídos da comunidade eclesial.
}

Este movimento inspirou a formação de outros grupos, como o Grupo de Ação Pastoral da Diversidade de São Paulo, o grupo Diversidade Católica do Paraná, o grupo Diversidade Católica de Ribeirão Preto e Região, dentre outros. Em julho de 2014 houve o primeiro encontro nacional dos integrantes destes grupos, promovido e organizado pelo grupo do Rio de Janeiro..

\section{Considerações finais}

A sexualidade é fruto de uma transformação social. Há, portanto, a necessidade urgente de um debate profundo, desprovido de preconceitos, sobretudo ouvindo os testemunhos daquelas e daqueles que são excluídos de suas comunidades religiosas, por pura falta de entendimento, compreensão e compaixão, por parte de seus integrantes, em especial as lideranças.

Pode-se perceber que esta questão merece um cuidado maior, atualizando a interpretação bíblica em observação ao contexto de época na escrita destas narrativas, também às particularidades sócio antropológicas que norteiam as relações eróticoafetivas da atualidade.

Espera-se da comunidade cristã um abraço eloquente ao cristianismo, que promova a paz, o acolhimento e o amor incondicional pregado por Jesus. 


\section{Referências}

APPOLINÁRIO, F. Dicionário de metodologia científica: um guia para a produção do conhecimento científico. São Paulo, Atlas, 2009.

Associação Brasileira de Normas Técnicas. NBR 6023. Informação e Documentação: referencias: elaboração. Rio de Janeiro. 2002

Bíblia de Jerusalém. São Paulo: Paulus, 2002. Tradução do original em língua francesa: Les Éditions Du Cerf, Paris, 1998.

Bíblia do peregrino. $2^{\mathrm{a}}$ ed. São Paulo: Paulus, 2006.

Bíblia sagrada. Trad. ALMEIDA, J. A. Barueri, SP: Sociedade Bíblica do Brasil, 1993.

Bíblia sagrada: edição catequética popular. São Paulo: Editora Ave Maria, 2012.

Bíblia sagrada: edição da família. Petrópolis, RJ: Editora Vozes, 2001.

Bíblia: tradução ecumênica. 2a ed. São Paulo: Edições Loyola Jesuítas, 2015.

ENDSJO, D. O. Sexo e religião: do baile de virgens ao sexo sagrado homossexual. São Paulo: Geração Editorial, 2014.

FRANCISCO, E. F. Antigo testamento interlinear hebraico-português. Vol. 1: pentateuco. Barueri, SP: Sociedade Bíblica do Brasil, 2012.

GIL, C. Como elaborar projetos de pesquisa. 4a . Edç. São Paulo, Atlas, 2002.

HELMINIAK, D. A. O que a Bíblia realmente diz sobre homossexualidade. São Paulo: Summus, 1998.

JUNQUEIRA, S. R. A. et. al. Amor sacralizado e o amor banido: gênero, orientação sexual e espiritualidade. Curitiba: CRV, 2015.

LIVERANI, M. Para além da Bíblia: história antiga de Israel. São Paulo: Edições Loyola, 2008.

MOSER, A. O enigma da esfinge: a sexualidade. São Paulo: Editora Vozes, 2001.

MUSSKOPF, A. S. Via(da)gens teológicas: itinerários para uma teologia queer no Brasil. São Paulo: Fonte Editorial, 2012.

Novo testamento interlinear grego-português. Barueri, SP: Sociedade Bíblica do Brasil, 2004.

PEDROSA, T. D. L. Arqueologia e interpretação: a criação de dois modelos arqueológicos para a Amazônia. PUC-RS: Pontifícia Universidade do Rio Grande do Sul. Porto Alegre: Programa de Pós-graduação em História. 2008. Dissertação (Mestrado).

QUINET, A. e JORGE, M. A. C. (org.). As homossexualidades na psicanálise: na história de sua despatologização. São Paulo: Segmento Farma, 2013.

RAMIRES NETO, L. Habitus de gênero e experiência escolar: jovens gays no ensino médio em São Paulo. FEUSP: Faculdade de Educação da Universidade de São Paulo. São Paulo: Programa de Pós-graduação em Educação. Dissertação (Mestrado).

SOUZA, J. O. M. L. Terapias do "armário": clínica, ética e homofobia. UniCEUB: 
Centro Universitário de Brasília. Brasília: Bacharelado em Psicologia. Monografia (Conclusão de Curso).

TORRES, M. L. A evidência linguística e extralinguística para a tradução de arsenokoitai. Revista Hermenêutica, Seminário Adventista Latino-americano de Teologia. Disponível em: https://getiunasp.files.wordpress.com/2012/06/artigo-sobrearsenokoitai_milton-torres.pdf; também em: http://www.seeradventista.com.br/ojs/index.php/hermeneutica/article/view/270. Acesso em: $17 \mathrm{de}$ janeiro de 2017.

TREVISAN, J. S. Devassos no paraíso: a homossexualidade no Brasil, da colônia à atualidade. $5^{\text {a }}$ ed. Rio de Janeiro: Record, 2002. 